\title{
The Impact of Persian Language on Indian Languages
}

\author{
Ali Akbar Khansir \\ Bushehr University of Medical Sciences, Bushehr, Iran \\ Nasrin Mozafari \\ Bushehr University of Medical Sciences, Bushehr, Iran
}

\begin{abstract}
The purpose of the paper is to examine the impact of Persian language on many Indian Languages like Bengali, Punjabi, Urdu, Gujarati, Telugu, and Hindi etc. For historical reasons, Indian languages have borrowed a great number of Persian words and phrases from Persian language that they have been using in the society of India. Old Persian Language, Middle Persian Language, and Modern Persian Language will be examined .Many Indian languages and Persian languages are part of the Indo-European languages. India and Iran have always had close relationship with each other; this relationship has been observed even before the advent of Islam. The time of Persians king was available trade ties between two nations who travelled with their ships and passed from Persian Gulf to Indian Ocean. The above Indian languages will be discussed briefly in this paper.
\end{abstract}

Index Terms-Persian language, Indian languages, old Persian language, middle Persian language, modern Persian language

\section{INTRODUCTION}

The aim of this brief article is to highlight the impact of Persian language on Indian Languages.

Gleason (1961) pointed out that "Indo-European is the largest and most important language family, from the point of view of both the social importance of the major language in the group, and their interest to linguists. The term IndoEuropean is applied to the family of languages that spread initially throughout Europe and several parts of south Asia and that are in modern times used in every part of the world. This family is divided into several sub-families or branches or groups, each of which comprises several languages "(cited in Varshney1998, p. 403). Persian language as one of the branches of Indo-European languages has had a major linguistic and literary influence on Indian Languages. Safavi (2006) argued that "all Indian languages like Bengali, Punjabi, Marathi, Gujarati, Telugu, and Hindi etc. contain a great number of Persian words and phrases for which they have no synonym"( $\mathrm{p}$. ix). Persian language was spoken Middle East, and Asia countries roughly from $1000 \mathrm{AD}$ to $1800 \mathrm{AD}$ and it was used as lingua-Franca of many countries over the world. The Persian language was used as a second language in South Asia it was served as the language of culture and education in several Muslim Courts in South Asia and became the sole official language under the Mughal emperors. During the power of Mughal in India, the culture and education of India was influenced by Persian language and the relationship between two nations in literature and science was at its peak and Persian language was official language of India. In this time, almost all languages of India have been influenced by Persian language not only in India literature but also in the speech of the common people. Persian language has had strong influenced on Urdu, Punjabi, and Sindhi in India. Other Indian languages like Hindi, Gujarati, Marathi, and Rajasthani have borrowed a great number of Persian words and phrases from Persian language. Safavi (2006, p. ix) indicated that "Mughal kings patronized Iranian poets and scholars and the impact of Persian culture and language is discernable on all aspects of intellectual and socio-cultural life of India. Indian officers and nobles employed at the court, wore Iranian dress, spoke Persian language and enjoyed Persian poetry". She added that "From the East to West this synthesis of two cultures can be observed in architecture, painting, music, and poetry. Agra, Fatehpur Sikri, the Deccani mosques and mausoleums, Maharaja Ranjit Singh's forts, many Gurdwaras, Akbar's tomb at Sikandra and of course the Taj Mahal are eyecatching examples of the Persian influence"( p. ix). According to Nizami (2013), the Persian language had influenced on all aspects of Indian life, such as political, literary, cultural, and religious aspects. He added that in the history of India during the medieval period, a number of Iranian cultural streams in the realm of polity, social traditions, literature, historiography and mystic thought seem flowing in every direction enriching the soil and contributing to the variegated culture pattern of India. It was generally believed in India during the Sultanate period that kingship was not possible without emulating Persian customs, ceremonies and principles of government.

The role of Persian language in India was very important and it was used as the second official language of India, The Persian language considered as the language of culture and science of Subcontinent, before the British colonized India. The Persian language was replaced by English Language in India in 1832. Before 1832, the Persian language was spoken by people from Sind to Bengal. The Farsi language is used among the Indian people as only the same language 
among them where as Indian languages differed from group to group and the people had the different dialects in every place of Subcontinent.

\section{The History OF PERSiAn LANGUAGE}

In the case of the history of Persian language, Persian language is known as one of the oldest languages in the world, this language is directly related to Indo-European language and it is known in the world as a branch of Indo-European language and it has root in the history of human being and came back to Aryans group were an old group arrived to Persia area from western Asia. Rashidvash (2012) mentioned that among the earliest civilizations in Mesopotamia, Iran was inhabited by human. But Iranian history dates back to 3200 BC. The first dynasty was Achaemenids, and the great founder of this empire was Cyrus. In addition, he was the first emperor established the charter of human rights and this empire was overthrown by Alexander the Great in 330 BC was empire of Seleucid Greek Dynasty. In this discussion, we consider briefly the history of the Persian language from Old Persian language to Modern Persian language. Old language in Iran is referred to Achaemenid Iranian language (until $400 \mathrm{BEC}$ ); this language is related to Avestan or Zarathshtra language. Fekri- Ershad and Mehrabi (2006) divided the Iranian old language into the four parts: 1. Old Persian, 2. Avestan, 3. Sacian, and 4. Median. Abolghassemi (1994) indicated that in the beginning of the first Millennium B.C., one of the Iranian Arian groups settled down in the high grounds of Iran, thus; old Persian language became independent language and the language prevailed in the area along with the other local dialects were used by the people. What we get information from period of old language, was based on Hinz (1973)," this language, like many other old languages had some peculiarities which underwent many changes during different times" (cited in FekriErshad and Mehrabi 2006, p.202). Bartholomae (1901) mentioned some of these peculiarities as follows:

1. The old Persian vocabulary had three forms of weak, gund (strong), and vrdchli (stronger), and each form served a special purpose. In other words, the stem of each word appeared in the lexicon in one of these three forms.

2. The nouns had three genders: masculine, feminine, or neutral, in ingular, dual and plural form. All nouns could syntactically fall in one of the eight cases: nominative, accusative, vocative, instrumental, dative, ablative, genitive, and locative, the nouns, according to the sound in which they ended, had special conjugation in these eight cases.

3. Pronouns, too, were conjugated in the eight cases above mentioned and had three genders and three numbers, but personal pronouns had no gender.

4. Adjectives were conjugated according to the gender, number, and case of the nouns they modified.

5. In Old Persian, many inflections were derived from the verbal roots each of which was used for a special purpose. Verbs had different modes; e.g. indicative, imperative, optative, conjunctive and injunctive. They had three voices: active, passive and middle. Different forms were made by adding the marker to the verb stem (cited in Fekri- Ershad and Mehrabi 2006, p.202).

Old Persian language used as an official language in the Old Iranian society spoken by Iranian people in the dynasty of Achaemenid kings such as Cyrus and the great Darius. In addition, their empire was overthrown by Alexander the Great. Middle Persian language started before the Iranian accepted Islam as an official religion. Middle Persian language is referred to 400 BCE-900CE. In this time, Iran was under empire of Sassanid, there are many languages, thus; two important languages used as official languages spoken by the Iranian people: Sassanid' language spoken in western south of Iran and the other language was spoken in the western north of Iran called the Parthian language. Fekri- Ershad and Mehrabi (2006, p. 203) mentioned some of the important features of Middle language as follows:

1. The phonological system of Middle Persian, which was based on Old Persian phonemes, was in fact considered as something between Old and New Persian, and by comparing these two systems we can understand its phonology. This comparison tells us that the phonemes of that period underwent changes in some aspects before they reached the next period.

2. Because of the phonetical changes and morphological endings, the Middle Persian vocabulary became shorter and simpler. For example, the adjective "kapautaka" changed to "kabod" after transition from Old Persian to Middle Persian.

3. In Middle Persian, nouns and pronouns lack gender and the number of 'dual' has disappeard.

4. The eight cases of nouns and pronouns limited to two forms of casus rectus and cases obliquus.

5. With the decrease of the eight cases, there was a need for prepositions. Prepositions were added to the syntax one by one.

6. The system of verbs, which was previously very comprehensive and complicated, became a lot simpler. Among the different modes of verbs, the injunctive did not transfer to Middle Persian, and the other modes were confined to two forms: present and past.

In addition, before Iran was attacked by the Muslim Arabs in the $7^{\text {th }}$ century, the major important language was written by Iranian people was 'Pahlavi'. In this time, the role of much simplification of inflection grammatically, was taken placed in Middle Persian language. New Persian language appeared along with changes from Middle Persian language, in this time, Arabic vocabulary appeared in the language of Iranian people. Iranian people accepted Islam as an official ideology and the modern Persian language used by Iranian in new period was similar to Arabic language based on alphabetically, but the two languages were not similar in vocabulary and grammar, and their families were different. In addition, many Arabic words were used by Iranian speakers in order to communicate with themselves. New Persian language developed in $8^{\text {th }}$ century after the empire of Caliphate at Baghdad in the $9^{\text {th }}$ century was overthrown 
and Dari language as new language accepted by the Iranian people as independent language and this language used in many areas such as Tajikistan, Uzbekistan, Afghanistan, India, Pakistan, Turkmenistan and many other countries . The accepted of the new language was along with changes in the Middle Persian language, Fekri- Ershad and Mehrabi (2006, p.204) indicated most important of the changes as follows:

1. There happened some slight changes in the Persian phonetic system; some old phonetic forms can be traced in some Persian dialects of today.

2. The writing system, once again, changed and some other forms such as Naskh and Nastealigh replaced the old one.

3. The most important change that took place in this period was the appearance of Arabic vocabulary in the language, and by passing of time, the vocabulary of other languages such as Turkish, France, Russian, English, etc. joined Persian.

However, the modern Persian language in some other countries such as Western countries is known as Farsi language. Another name of Farsi is called Persian, Iranian 'Farhangestan' as the official the Persian Language and Literature Academy use Persian word instead of Farsi word in cultural, diplomatic and scientific communication over the world.

\section{ThE INDIAN LANGUAGES}

The major Indian languages are closely related to Persian language; in this paper briefly discussed: Urdu, Bengali, Punjabi, Gujarati, Telugu, and Hindi. They are prominent languages of India among the other Indian languages have been more influenced by Persian language during the period of the interaction between two nations. Urdu is one of the important Indian languages was born as independent language in the end of the $4^{\text {th }}$ century AD. This language is more spoken by the Indian Muslim groups over India. This language was born out of the interaction between Persian language and Hindi language and thus, Urdu borrowed many Arabic words, the Arabic words along with Persian and Hindi words made the basis of Urdu language. When Turks and Mongols came to India, they introduced Arabic and Persian languages. The most important reason for the development of Urdu language was the interaction between the Turkish people and soldiers with common people in Delhi after, the conquest of Delhi. In $18^{\text {th }}$ century, Urdu has influenced on Indian literature and in this time, this language became more important and popular language over Subcontinent and it has found its prominent place in Indian society. Urdu language is one of the Indo-Aryan branch of the Indo European languages, thus; it used as an official language of Muslim groups and in Pakistan country is spoken as their national and lingua franca. Bengali is one of the major important languages in India has been influenced by Persian language in the history of Subcontinent. Bengali is one of the families of Indo-Aryan language. It is mother tongue of west Bengal people and Bangladesh nation. Tahir Ali (2006) defined Bengali language as one of the sweetest language around world and $\mathrm{He}$ added that this language has a very literature in prose and poetry both. According to Tahir Ali (2006), the history of Bengali language divided into three periods as follows:

1. The old Bengali Period;

2. The middle Bengali period;

3. The modern Bengali periods.

The old Bengali period came back to 950 A.D. and continued up to 1200A.D. The middle Bengali period started from 1200 A.D. TO 1800 A.D. The modern Bengali period started from 1800 A.D. and it is still used as native language of Bengal people in Subcontinent. In addition, before the advent of Muslim rule, the Sanskrit was more interested in the area more than Bengali language by the Bengal people. Punjabi is one of the Indian languages has been influenced by Persian language in Subcontinent. This language likes Bengali language is one of the families of Indo-Aryan language, thus; it is mother tongue of the Norwest of Indian people and part of Pakistan. Punjab language as one of the independent languages of India appeared in the $12^{\text {th }}$ century, thus; this language used by the huge population of Sikhs in Punjab. Punjab language has influenced on Indian cultures, today, we can see that the role of this language is very important in Indian Bollywood cinema, in addition, some poets and songs written by great Indian poets in Punjab language used by Indian artists in Bollywood cinema. This language used among the Indian people in other countries such as England, Wales, U.S.A, Canada, and Arab countries. It is known as the first official language of the Indian states of Punjab. Hindi language is known as one of the three Indian educational languages (English, Hindi, and Local language) in Subcontinent. It is one of the official languages of Indian people in India and it is recognized by the Indian government as language communication along with English language for the union government in Subcontinent. Hindi language is called as one of the members of Indo- Aryan groups and one of the branches of Indo-European Language spoken by Indian people in India and over the world. It is also known as the fourth spoken language speaking in the world. If we come the history of Indian languages, we pay attention that Hindi was part of Urdu language , today; linguistically, both of them are the same language, and belong to Indo-European language, thus; Hindi language was born out of the interaction among Arabic, Persian, English, even Sanskrit words. There is only written difference between Urdu and Hindi languages is that Urdu language is written in a Persian -modified Arabic scripts whereas Hindi is written in the Devanagari script (Watkins, et al, 2013). After independence of India, the government of India released the following conventions:

1. standardization of grammar: In 1954, the Government of India set up a committee to prepare a grammar of Hindi; The committee's report was released in 1958 as "A Basic Grammar of Modern Hindi" 
2. standardization of the orthography, using the Devanagari script, by the Central Hindi Directorate of the Ministry of Education and Culture to bring about uniformity in writing, to improve the shape of some Devanagari characters, and introducing diacritics to express sounds from other languages.

In addition, Hindi language is used more than other Indian languages in Indian movies in India.

The one of the Indian language, we consider it, it is called Gujarati. Gujarati belongs to Gujarat area in India and the official language of the West India and thus; it is one of the members of Indo- Aryan groups and one of the branches of Indo-European Language. Historically, this language divided into three parts: Old Gujarati language started from AD 1100 to 1500 , Middle Gujarati language was between AD 1500 to 1800, and new language of Gujarati recorded from $\mathrm{AD}$ 1800. Gujarati language is the fourteen regional Indian languages among the twenty-two official languages in Subcontinent. This language was the mother tongue of the great leader of India, Mahatma Gandhi. The last Indian languages is considered in this paper is Telugu. Telugu is one of the branches of the Dravidian language; it is used as the official language of Andhra Pradesh State. Telugu language, Except; Hindi and Bengali languages; is known as the third most spoken language in Subcontinent. Historically, this language divided into the four periods: the first period came from $200 \mathrm{BEC}$ to $500 \mathrm{CE}$; the second period started from 500CE to $1100 \mathrm{CE}$; the third period was between $1100 \mathrm{CE}$ and 1400CE; and the last period started from 1400CE to 1900CE. Thus, this language also used as one of the movie languages in Indian Bollywood cinema in India. The aim of this part of the article was to familiar briefly the audiences with Indian languages are closely related to Persian language

\section{Persian LANGUAge Influence ON INDiAn LANGUAGES}

The aim of this brief paper is to highlight a few important features of the Persian language which enriched the Indian languages during the history of the relationship between the two nations. One of the best interactions between the Iranian and Indian nations came to the period of The Mughal rulers in India. In this time, the impact of the Persian language has been seen on all aspects of life of Indian people such as their culture, language, the most important of this relationship between Iran and India came to the influenced of Iranian culture and language on India language and culture is that in this time, we can see emergence of an entirely new style of poetry and prose in India literature, according to Safavi (2006, ix)," the interaction of Indo-Iranian cultures also gave birth to a new language 'Rekhta or Urdu' which is a synthesis of Hindi, Persian and Arabic words." In discussion of the influence of Persian language on Indian languages, the discussion is considered briefly as follows:

One of the official Indian language was under influence of the Persian language is Bengali language, or language of the west Bengal people. In the early $13^{\text {th }}$ century Bengal was conquered by Muslim, leader, namely Ikhtiyaruddin bin Mohammad Bakhtiar Khilji. From this period, Bengal people accepted new culture, according to Tahir Ali (2006) Bengali people tried to learn new language (Persian), thus; number of the Persian words, phrases and idioms which enriched their language. He added that "Muslims Sufis, who had already reached Bengal and settled here even centuries before the advent of Muslim rule, also played, directly and indirectly, an important role in the development of Bengali language and literature. In fact, it was the preaching of the Muslim Sufis of Bengal through which Persian mystical elements as well as Persian words and thoughts started penetrating into Bengali poetry" ( p.2). The role of the Persian language was very vital in the progress of Bengali poetry; we can see hundreds of the Persian words in poetry of Bengal; even after the establishment of Muslim rules in the area. Some the famous Persian books' stories and poets translated into Bengali language such as Laila and Majnu, Hafiz Shirazi, (Hafiz Shirazi is a Great poet in Iranian literature and very famous over the world), Yusuf and Zulaikha, etc.

One of the official languages of Indian people has borrowed a great number the Persian words and phrases and idioms is Urdu language. We said that Urdu language was born out of the interaction between Persian and Hindi and Arabic languages. Bahri (1960, p. 9) argued that" the most important influence of Persian on Hindi, it has been recognized, was the growth and development of Urdu language and literature." Historically, Urdu word has been derived from Turkish term which was used military station during the period of Mughal rule in India. Urdu language like Bengali language was under influence on Persian language, what it is very clear, is that impact of the Persian language and literature on Urdu has been considered, according to Bahri (1960) Urdu literature adopted Persian literature in form and conception, in addition even in feeling, and in local colouring. Many Persian books such as Leila and Majnu, Shirin and Farhad, and Yusuf and Zulaikha which have been famous in Iranian culture translated into Urdu language. In discussion of the relationship between the two languages, particularly, in the form of poetry, Urdu language adopted the impact of the Iranian poetry (Persian poetry as one of the richest poetry in the world and it always bless the literature of human being in the during history of mankind). Many great Iranian poets have influenced on Urdu poetry, many Urdu poets such as Wali,Mir, Sauda and Insha used the Persian vocabularies in their poems. Many Persian vocabularies have been used in Urdu language along with compound with an Urdu word ' karna or كرنا كردنع' are expressed as follows:

Persian word qahbool kardan shak kardan mahroom kardan negah kardan
Urdu word

(qahbool krna) قبول كرنا شك كرنا (shak krna)

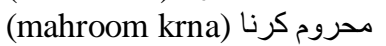
نغاه كرنا (negah krna) نكا
English word

accept

suspect

deprive

look at 

safar kardan
(safar krna) سفر كرنا
travel

In addition, the decline of the Persian language as a vehicle of Urdu literature as one of the official Indian languages began rapidly in the Mughal period comeback to the death of Aurangzeb was one of the Mughal Emperor. In the time of British Empire in India, Urdu was favoured by the British more than Hindi language. For historical reasons, "they soon discovered that it was easier to win over the Muslims than to appease the Hindus. It was; therefore, politically expedient for the British to encourage Muslim institutions (Bahri, 1960, p.13)."

Hindi language used as one of the three official Indian languages ( Hindi, English, and Local language) in Indian educational system and also it used as lingua franca in order to link Indian people in Subcontinent. In the history of India, Hindi language has basically been influenced by Persian language. Hindi language or Hindu language as one of the major important Indian people language adopted by government of India as an official language along with English language in India, regarding to the important of English language in India, after India revolution in 1947; the great prime minister of India, Nero argued that we need English language as language that can help to us communicate with all of people in the world and open the window of knowledge and science towards to India. According to Bahri (1960), the period of Persian influence, started with establishment of Muslim Rule in Delhi and ends with the fall of British Power in India. The history of the influence of Persian language on Hindi language divided into seven items, and according to Bahri (1960) the influence of Persian language on Hindi language has been more than seven centuries. Historically, the seven periods are written, briefly as follows:

1. From 1200 to 1400 A.D., this period is called negligible influence of Persian language on Hindi language;

2. From 1400 to 1600 A.D., this time is called tangible influence of Persian language on Hindi language;

3. From 1600 to 1750 A.D., this age is called harmony among classes and there was period of healthy political and social co-operation between Muslims and Hindus. In this time, Akabr king was ruler, the political harmony was initiated by Akabr and social harmony by Sufis and Bhaktas.

4. This age started from 1750 to 1836 . Urdu language was born and used as a form of literature in northern India. Hindi language is considered as a common medium of literature for Hindus as well as Muslims. In this time, Persian language has influenced on Hindi language normally and without any forced. This period is also called the golden age of Hindi literature.

5. This period started from 1837 to 1900 , we call the period of over-emphasis on Arabo-Persian due to the organized patronage of Urdu by the British and consequent suppression of Hindi in Northern provinces of India. In this period, Hindi language has been influenced by Persian through Urdu in its all spheres of life: education, administration and correspondence, besides literature, thus; Hindi imitated Urdu.

6. This time is known as a reaction against over-Persianization began from 1900 when Hindi language used as an alternative court language in U.P state in India and Persian words and forms still used in speech and literature, thus; this period is called the time of toleration. All India started pro-Sanskrit tendencies which have ever grown in all aspects of their life and which have given a severe setback to the influence of Persian language.

7. The last period of the influence of Persian language on Hindi language came back to the $20^{\text {th }}$ century, in this era, Hindi language adopted as the official language of the Union of India. This language has been recognized in Devanagari and then it used in India script instead of Urdu and Persian scripts.

Even today, the largest numbers of Persian words are available in Hindi language used in the society of India among people of Subcontinent. A number of the Persian words have been borrowed by Hindi language are mentioned as follows:

$\begin{array}{ll}\text { Persian } & \text { English } \\ \text { asman } & \text { sky } \\ \text { kalam } & \text { pen } \\ \text { rah } & \text { way } \\ \text { tang } & \text { narrow } \\ \text { zahar } & \text { poison } \\ \text { iman } & \text { faith } \\ \text { avaz } & \text { voice } \\ \text { khat } & \text { letter }\end{array}$

In addition, many the other Indian languages such as Gujarati, Telugu, and Punjabi have been influenced by Persian language during the period of Persian language had power in India. Many Iranian texts and books have been translated into Gujarati, Telugu, and Punjabi languages. Today, the impact of Persian language can be seen in written and spoken of the languages and Persian words still exist in Gujarati, Telugu, and Punjabi .

\section{CONCLUSION}

In this conclusion, first, Iranian language is historically considered and then the influence of the Persian language on Indian languages mentioned. The Iranian languages include Persian (Farsi), Pashto (in Afghanistan and Pakistan), Kurdish (in much of Middle East), Ossetic (in the Caucasus), and a large number of smaller languages. The Persian language spoken in Tadjikistan is called Tadjik. Two important Iranian languages: Avestan was the language of 
Zoroastrian religious texts and Old Persian language was the language of the Persian Empire (Trask, 1996). Many Indian languages are the branch of Indo-Aryan language contains Hindi, Urdu, Gujarati, Panjabi, and Bengali.

The first shape of Iranian civilization in India was Persian language developed by Mughal period. The Persian language became the official and government of India, in that time, Mughal had power, specially "Akbar" was one of the powerful emperors developed the Persian language as the official language of this empire and Indian people had adopted this language more than the other languages such as Arabic language. The Persian language became the language of diplomacy, main language (administration) of India. Therefore, Indian People have borrowed a number of The Persian words and many Indian poets and writers adopted it as the language of poetry and literature. Today, a number of the Persian language are available in the poetry and literature and even in Indian local languages. In 1832 the Persian language was replaced by English language when British entered in India.

Thus, regarding what has been presented in this paper, Indian people adopted the influence of the Persian language on their languages and cultures and this relation was closer ties between two nations in the time of Akbar emperor in the $16^{\text {th }}$ century.

\section{ACKNOWLEDGEMENT}

I affectionately dedicate this paper to my teacher, Dr. Jennifer, M.Bayer.

\section{REFERENCES}

[1] Abolghassemi,M. (1994). A History of the Persian Language. Tehran: The Center for Studying and Compiling University Books in Humanities.

[2] Bahri, H. (1960). Persian Influence on Hindi. Bharati Press Publications, Allahabad: India.

[3] Bartholomae, C. (1901). Vorgeschichte der Iranischen Sprachen (Grundriss der Iranischen Philology 1). Strassburg: Verlag von karl J. Truebner.

[4] Fekrl-Ershad, J. \& Mehrabi, F. (2006) An Investigation into the Prehistory of the Persian Language. Indian Journal of Applied Linguistics, 33(1), 199-207.

[5] Gleason,H.A. (1961). Introduction to Descriptive Linguistics,Holt, Rinehart, Winston: New York.

[6] Hinz,W. (1973). Neue Wege im Altpersischen. Wiesbaden: Harrassowitz.

[7] Nizami, K. A. (2013). Persian Influence on Literary and Sufi Traditions in South. Asia. http:/daftareroshan.blogfa.com/cat45.aspk.retrieval time, 2013, 03/21.

[8] Rashidvash V. (2012). History of Iran: The Circumstances of Signing Golestan and Turkmanchy Treaties and its Contents. International Review of Social Sciences and Humanities 3(1):246-261.

[9] Safavi,A.D. (2006). Introduction. International Seminar on Impact of Persian Language and Culture on India, Department of Persian, Aligarh Muslim University, Aligarh: India.

[10] TahirAli, H.M. (2006). Impact of Persian on Bengali Poetry. International Seminar on Impact of Persian Language and Culture on India, Department of Persian, Aligarh Muslim University, Aligarh: India.

[11] Trask, R.L. (1996) Historical Linguistics. Arnold: London.

[12] Varshney, R.L. (1998). An Introductory Text Book of Linguistics and Phonetics. Student Store: Rampur Bagh, BAREILLY243001.

[13] Watkins, T., Valley, S. \& Alley. (2013).The Nature of the Urdu Language. http:/www.sjsu.edu/faculty/Watkins/urdu.htm, retrieval time, 2013/03/26.

Ali Akbar Khansir is an Assistant professor in English Language Teaching at the Bushehr University of Medical Sciences, Bushehr, Iran. He has completed M.A. in English Language Teaching at the Aligarh Muslim University in 2003 and PhD in English Language Teaching at the Mysore University in 2010 in India. He has published some articles in the field of Applied Linguistics and English Language Teaching in Academic Journals of English Language Teaching and Linguistics and published two books: English Error Analysis in 2010 and English Spelling and Sound in 2012 in Germany.

Nasrin Mozafari is an Assistant professor in Persian Language at the Bushehr University of Medical Sciences, Bushehr, Iran. She has completed PhD in Persian Language at the Tehran Payame -Nour University. She has published some books and articles in the field of Persian language. 